\title{
EL TERRITORIO FLUVIAL Y SUS DIFICULTADES DE APLICACIÓN*
}

\author{
Alfredo Ollero Ojeda1, Askoa Ibisate González de Matauco² \\ Josu Elso Huarte ${ }^{3}$ \\ 1 Dpto. de Geografía y Ordenación del Territorio, Universidad de Zaragoza. \\ Pedro Cerbuna, 12, 50009 Zaragoza \\ aollero@unizar.es \\ 2 Dpto. de Geografía, Prehistoria y Arqueología, Universidad del País Vasco. \\ Tomás y Valiente s/n, 01006 Vitoria-Gasteiz \\ ${ }^{3}$ Gestión Ambiental Viveros y Repoblaciones de Navarra, \\ Padre Adoian, 219, 31015 Pamplona
}

\begin{abstract}
Resumen: El espacio fluvial que corresponde al río y que ha modelado con su propia dinámica ha sido aprovechado y ocupado por el hombre. Así en la mayor parte de los cursos fluviales existe una problemática que, marcada por el deterioro ambiental y el incremento de los riesgos, deriva de la incompatibilidad entre la dinámica natural y la antropización del sistema. La solución viene dada por aplicar un territorio fluvial, un espacio que permita conservar o recuperar la dinámica hidrogeomorfológica, obtener un corredor ribereño continuo que garantice la función ecológica, bioclimática y paisajística del sistema fluvial, cumplir con el buen estado ecológico (Directiva 2000/60/CE), laminar de forma natural las avenidas, resolver problemas de ordenación de áreas inundables, mejorar y consolidar el paisaje fluvial. Se presentan distintas propuestas de aplicación del Territorio Fluvial en la cuenca del Ebro. Su aplicación no ha sido posible salvo en casos muy concretos, debido a importantes dificultades: conflictos de propiedad, multiplicidad de usos e intereses de complicada compatibilización, situaciones heredadas, o la dificultad para integrar esta medida con la gestión de caudales y otras medidas ambientales. El Territorio Fluvial está científicamente consolidado como modelo de actuación técnicamente viable. Sin embargo, en España cuenta con reticencias en ámbitos políticos y administrativos y todavía no se valora como medida de resolución de problemas ambientales y de riesgos por sus dificultades de aplicación y gestión.
\end{abstract}

Palabras clave: territorio fluvial, dinámica hidrogeomorfológica, corredor ribereño, llano de inundación, riesgos de crecida.

${ }^{1}$ Recibido: 8-01-10. Aceptado: 27-04-10. 


\begin{abstract}
The fluvial space shaped by the river with its own dynamics and where its processes take form, has been occupied for long time. So in most of the rivers an environmental worsening and the increase of the risk arises from the conflict between the natural dynamics and the human use of the system. The solution comes from the implementation of a Fluvial Territory, a space where the river's dynamics could act, and change with it, so it can preserve or recover the hydromorphological dynamics, obtain a continuous riparian corridor that guarantees the ecological, bioclimatic and landscape function of the river system, fulfil the demands of the "ecological (Directive 2000/60/CE) good status", reduce in a natural way the floods, resolve land use planning problems of flooding areas, and ameliorate and consolidate the fluvial landscape. The presentation will show some experiences of proposals in Cinca, Ebre, Gallego, Arga and Aragon rivers. That implementation has shown enormous difficulties: property problems, many land uses and interest of difficult compatibility, inherited situations, or the hardness of integrating this measure with the flow management and other environmental measures, which has led to the impossibility of the application of the Fluvial Territory in most of the cases. The Fluvial Territory concept is scientifically consolidated as a model of action and it is technically feasible. However, spanish political and administration are very reluctant and still it is not valued as a way of resolving environmental and risk problems due to the difficulties of its application and management.
\end{abstract}

Keywords: Fluvial Territory, fluvial hydromorphology, riparian corridor, floodplain, flood risks.

\title{
1. Introducción
}

La red fluvial es un elemento clave en la dinámica ambiental y en la planificación territorial. Los ríos son sistemas naturales de máxima dinámica y complejidad. En el paisaje constituyen arterias fundamentales que dominan un espacio, un corredor estrecho y alargado con personalidad propia. La morfología de este espacio fluvial de fondo de valle ha sido construida por el propio sistema fluvial a lo largo de toda su historia, y sus dimensiones han sido definidas por los principales eventos de crecida a los que ese río ha asistido. De hecho, los sistemas fluviales construyen llanuras de inundación como sistema de auto-regulación, es decir, para reducir ellos mismos sus excesos. Por eso cada río ocupa exactamente el territorio que le corresponde, el que él ha creado, un espacio cuyas dimensiones son las adecuadas a los caracteres de la cuenca y del valle, a los caudales de crecida, a la pendiente, a la cantidad y profundidad de sus aluviones, etc. 
Ese espacio fluvial de fondo de valle ofrece diversas ventajas socioeconómicas. En consecuencia, muchos sistemas fluviales de destacables dinámicas hidrogeomorfológicas naturales han sido fijados por obras de defensa, con lo que se ha facilitado la progresiva ocupación humana de esos territorios, proceso que ha supuesto incremento de riesgos y ha provocado la pérdida muy extendida de un enorme patrimonio natural. En suma, en la mayor parte de los cursos fluviales existe una problemática que, marcada por el deterioro ambiental y el incremento de los riesgos, deriva de la incompatibilidad entre la dinámica natural y la antropización del sistema.

La solución frente a esa doble problemática se puede encontrar en la devolución a los ríos de una parte del espacio que se les había ido usurpando (Ollero, 2007). La restauración de ese "territorio fluvial" de suficiente anchura y continuidad permitiría reducir la peligrosidad de las crecidas y garantizaría la conservación y mejora de los ecosistemas acuáticos y ribereños. Esta solución es aplicable a cualquier sistema fluvial y a cualquier tipo de curso fluvial. No cabe duda, sin embargo, de que puede alcanzar su mayor utilidad en sistemas de llanura con notable anchura potencial del corredor ribereño y con problemática de riesgos por erosión e inundaciones.

En España, donde la problemática ambiental y de riesgos es especialmente grave y donde la restauración fluvial está muy poco desarrollada, la ordenación de áreas fluviales es una asignatura pendiente, como se constataba ya hace una década (Ureña, ed., 1999, Ureña y Ollero, 2000). Los avances al respecto en los últimos años han sido mínimos. De hecho, el deterioro de los ecosistemas fluviales ha ido en claro aumento y se ha generalizado. La mayoría de los problemas ni siquiera se diagnostican, porque no se consideran tales, y se agravan al seguir recurriéndose a soluciones exclusivamente ingenieriles y basadas en modelos únicos que no tienen en cuenta los caracteres específicos de cada tipo de curso fluvial (Ollero, 2008).

Estas inercias negativas explican el hecho de que en España no sea posible todavía implantar, ni siquiera en algunos casos que podrían servir de "banco de pruebas", la propuesta del Territorio Fluvial. En el presente trabajo se analizan los principios fundamentales de esta posible figura de ordenación y se explican sus dificultades de aplicación, con el objetivo de encontrar vías que faciliten la comprensión de los beneficios que esta medida podría conllevar. Los autores han participado en diversos encuentros internacionales sobre esta temática, el más reciente de ellos en Moulins (Francia) en octubre de 2009, y han debatido con sus colegas europeos la situación de cada país ante este modelo de planificación territorial en espacios fluviales. 


\section{El Territorio Fluvial}

\subsection{Concepto y antecedentes}

El concepto de Territorio Fluvial ha sido muy debatido y ha contado con diferentes expresiones en los últimos años: room for rivers, espace de liberté fluvial, free space for rivers, space to move, river widening, etc. La utilización en español del término "Territorio Fluvial" se estableció de forma consensuada en la mesa de trabajo sobre alteraciones geomorfológicas de cauces en la Estrategia Nacional de Restauración de Ríos (Ollero, coord., 2007). Dicha Estrategia Nacional adopta el Territorio Fluvial como una de las posibilidades más interesantes de la restauración fluvial, de ahí que el concepto pueda considerarse ya consolidado en España con esta terminología.

El Territorio Fluvial puede definirse como el terreno, espacio o paisaje dominado por un sistema fluvial. Es un espacio del río, que incluye el cauce, el corredor ribereño y, total o parcialmente, la llanura de inundación. Y se trata de un espacio a reivindicar, que choca con los intereses socioeconómicos sobre la red fluvial. Es una banda geomorfológica y ecológicamente activa, de máxima eficiencia y complejidad como sistema natural. Debe ser ancho, continuo, inundable, erosionable, no defendido y no urbanizable. Exige eliminar las defensas de margen y quitar o alejar las motas. Sus límites son precisos pero no deberían ser permanentes, sino que han de adaptarse a la movilidad fluvial. Debería ser una figura de ordenación del territorio, en concreto una adaptación de la misma a la Dinámica Fluvial. Precisamente por ello se optó por el término "territorio", de mayor concreción y posibilidad legal en el marco de la ordenación del territorio y la gestión ambiental. No tiene por qué ser un espacio público; puede mantener la propiedad privada con usos condicionados y prohibiciones (de nuevas edificaciones, de extracciones de áridos...).

En la figura 1 se integran los principales conceptos relacionados con los sistemas fluviales que hacen referencia al espacio fluvial, así como las relaciones e influencias entre todos ellos, que han llevado hasta el concepto de Territorio Fluvial.

En 1993 se proponía por primera vez la idea de la recuperación de un espacio fluvial con objetivos de restauración de la dinámica fluvial, mejora ambiental y mitigación de riesgos, con un proyecto de "Parque de Renaturalización de las Riberas y del Cauce Dinámico del Ebro" (Ollero, 1993a) aguas arriba de Zaragoza. Se trataba de un tramo de $28 \mathrm{~km}$ de cauce, con una superficie total de $2.271 \mathrm{ha}$, de las que 1.322 ha se encontraban cultivadas, incluyendo 341 ha de plantaciones de chopos. Esta idea para el Ebro fue expuesta en dos reuniones científicas en Avignon (Ollero, 1993b) y 


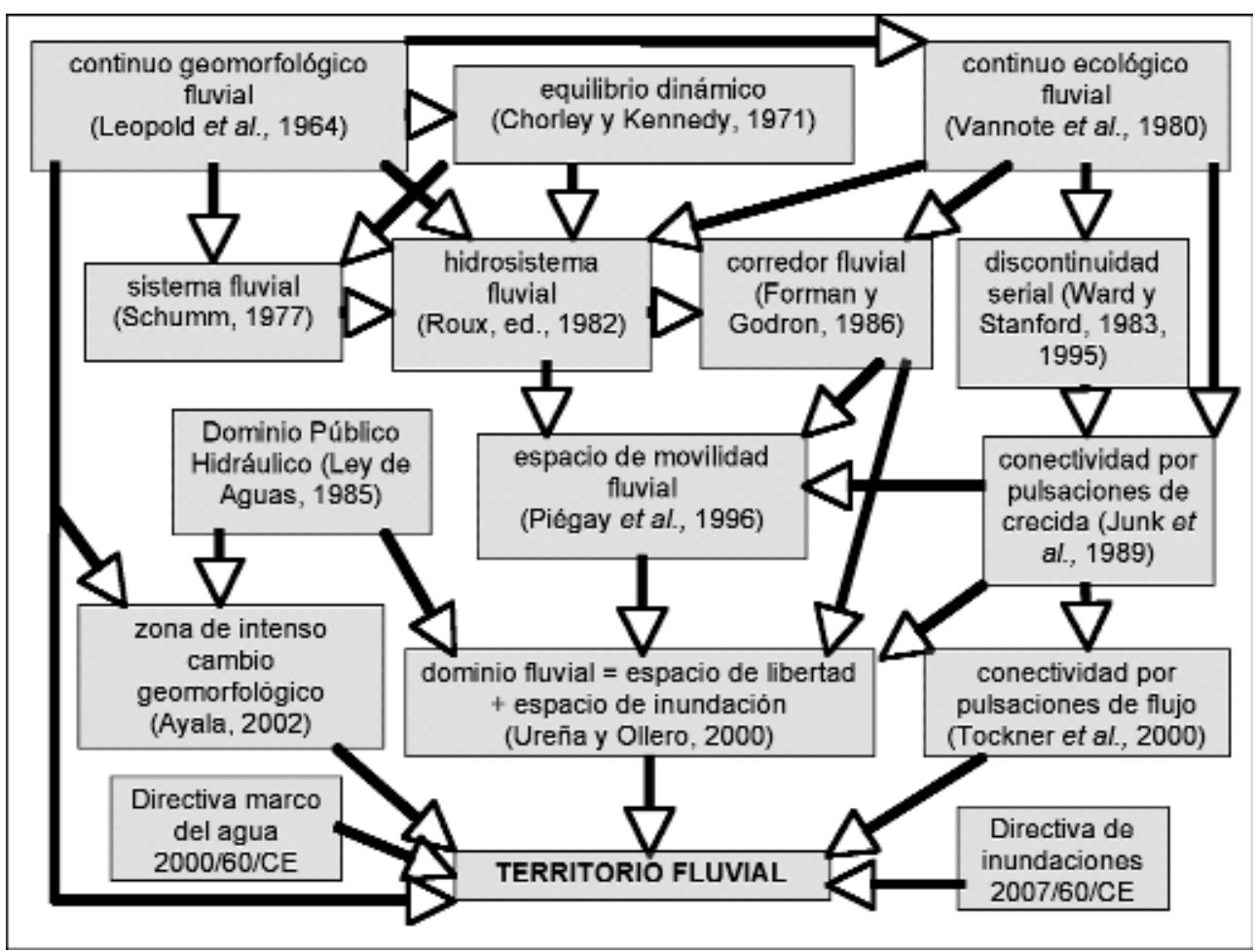

Figura 1. Ideograma evolutivo del Territorio Fluvial.

Lyon (Ollero, 1993c). En dichas reuniones se pudo constatar que algunos científicos fluviales franceses habían llegado a las mismas conclusiones, es decir, a la necesidad de devolver territorio a los ríos para mantener o recuperar su dinámica y sus ecosistemas y para reducir los niveles de riesgo. Las ideas francesas desembocaron en la figura del Espacio de Libertad Fluvial, desarrollada por el SDAGE RódanoMediterráneo-Córcega, definido como "el espacio del cauce mayor dentro del cual el canal fluvial (simple o múltiple) asegura translaciones laterales para permitir una movilización de los sedimentos así como el funcionamiento óptimo de los ecosistemas acuáticos o terrestres" (Piégay et al., 1996a,b; Bazin y Gautier, 1996; Malavoi et al., 1998, 2002; Piégay et al., 2005). La idea surge en Francia principalmente como vía de solución del problema de la incisión fluvial, derivada de siglos de explotación del agua y de los aluviones en numerosos ríos franceses, y causada también por efecto de los embalses y las defensas que constriñen los cauces. La incisión o erosión lineal del fondo del lecho había provocado, a su vez, descensos 
del nivel freático, desestabilización de puentes y grandes impactos en los ecosistemas acuáticos y ribereños. Así, los problemas ambientales para los que está más indicada esta solución son las alteraciones hidrogeomorfológicas provocadas por embalses y problemas derivados de la ocupación de terrenos, de la intromisión de infraestructuras longitudinales y transversales en las llanuras de inundación y de actuaciones de defensa.

En el ámbito anglosajón esta idea había sido ya esbozada en un trabajo de Palmer (1976) y se fue extendiendo bajo los conceptos de streamway (Brookes, 1996) inner river zone guideline (Dept. of Water Resources, 1998) o channel migration zone (Rapp y Abbe, 2003), como banda en la que la migración del canal es suficiente para mantener los ecosistemas y la movilidad de sedimentos. Kondolf et al. (2003) proponen la conservación o recuperación de esa banda fluvial activa (streamway), la de mayor eficiencia ecológica, con utilidad como espacio tampón y filtro entre los procesos hidromorfológicos y los intereses humanos del resto de la llanura de inundación, corredor capaz de soportar diversos usos y al mismo tiempo de mantener o lograr una alta biodiversidad. Pottier et al. (2005) han analizado y comparado las iniciativas británicas y francesas.

En Alemania Dister et al. (1990) habían propuesto ya esta medida para la gestión de la llanura de inundación del Rhin. En Holanda, en el curso bajo del mismo río y sus afluentes, se han ido poniendo en práctica sistemas de gestión de diques y de establecimiento de territorios fluviales (Cals y van Drimmelen, 2000; Vis et al., eds., 2001). En Suiza y Austria se han desarrollado diversos proyectos de ensanchamiento del espacio fluvial (Rohde et al., 2004, 2006; Habersack y Piégay, 2007). En Italia también surgió la propuesta de la fascia di pertinenza fluviale (Govi y Turitto, 1994), pero no se ha puesto en práctica.

En España retomaron la idea Ureña y Ollero (2000), proponiendo un cambio significativo en la definición administrativa de río y en la planificación de usos del suelo, con más espacio y continuidad y una definición menos permanente, variable a lo largo del tiempo y adaptada a la dinámica de cada tipo de curso fluvial. Apareció el concepto de Espacio de Movilidad por primera vez en un plan de ordenación fluvial en la restauración del impacto de la catástrofe de Aznalcóllar en el río Guadiamar (Montes, 2002; Guerrero y Baena, 2002).

\subsection{Objetivos y utilidad}

La necesidad de este concepto nace de la consolidación de importantes invasiones del espacio fluvial en los ríos europeos a lo largo del siglo XX. La restauración de la dinámica natural de los sistemas fluviales alterados será una labor prioritaria en el 
futuro. Si se pretende restaurar un sistema fluvial es preciso recuperar su dinámica natural activa, y para ello hay requisitos imprescindibles: caudales naturales, con fluctuaciones estacionales y procesos extremos, crecidas, auténticos motores de dinámica y de conectividad transversal, sedimentos que puedan movilizarse, ausencia de defensas e infraestructuras que pudieran encorsetar al cauce o dificultar los procesos de erosión, transporte y sedimentación y las relaciones ecológicas, así como presencia de vegetación natural complejamente estructurada que ejerza sus diversas funciones de filtro y controle la dinámica. Para todo ello es imprescindible contar con un espacio fluvial suficiente, continuo de arriba abajo para mantener las dinámicas naturales longitudinales y verticales y lo suficientemente ancho para cumplir la dinámica lateral y la conectividad.

Por otro lado, como solución para mitigar inundaciones es de sentido común. Porque la mejor manera de reducir la peligrosidad de un sistema fluvial es que el llano de inundación, o al menos una parte del mismo, ejerza su función principal, destacada por Mateu (1990), la de disipar la energía de las aguas de crecida almacenando caudal a lo largo del proceso. Así pues, el Territorio Fluvial debe tener la suficiente anchura y continuidad para lograr los siguientes objetivos, que constituyen su utilidad en la ordenación del territorio y en la restauración fluvial.

- Conservar o recuperar la dinámica hidrogeomorfológica, que el río pueda desplazarse lateralmente, erosionar, sedimentar y desbordarse, desarrollando todas las interacciones hidromorfológicas y ecológicas entre el cauce, las riberas, los anexos fluviales, la zona hiporreica y el freático. Así, el Territorio Fluvial contribuye a naturalizar el funcionamiento del río y a diversificar sus ambientes geomorfológicos (brazos, barras, microtopografías de decantación...), por lo que incrementa la diversidad ecológica en cauces y riberas propugnada por la Directiva Habitats (Comisión Europea, 1992). Por ejemplo, en cauces meandriformes libres sólo con un Territorio Fluvial podría volver a cambiar el cauce y se podrían volver a cortar meandros, generándose cauces abandonados que introducen una enorme biodiversidad en el sistema. Favorecidas por el Territorio Fluvial, las pulsaciones de crecida mantienen y regulan las biocenosis, siendo fundamental contar con espacios sin obstáculos en los que puedan darse todos los procesos bidireccionales.

- En ríos de llanura, por tanto, el Territorio Fluvial favorece la dinámica geomorfológica lateral, lo que enriquece la complejidad del sustrato aluvial. Al mismo tiempo, estabiliza la dinámica vertical, frenando los procesos de incisión típicos de ríos regulados con cauces constreñidos. Al frenar esos procesos se logra mantener un freático elevado, fundamental para las biocenosis.

- Obtener un corredor ribereño continuo que garantice la función ecológica, bioclimática y paisajística del sistema fluvial. Lograr unas riberas que ejerzan de 
espacio tampón natural y ecotono entre el cauce dinámico y el llano de inundación cultivado y humanizado, que mejoren la calidad del agua, que favorezcan la capacidad de recarga sedimentaria, impidan la incisión lineal de la corriente y mantengan alto el nivel freático.

- Cumplir con todo ello, al conservar las funciones, interacciones, dinámica, continuidad y conectividad de los ecosistemas fluviales, con la exigencia del buen estado ecológico que propugna la Directiva Marco del Agua (Comisión Europea, 2000).

- Laminar de forma natural las avenidas reduciendo los caudales punta por el propio desbordamiento dentro del Territorio Fluvial, que se convierte en almacén de ralentización de la onda de crecida, lográndose, por tanto, una mitigación del riesgo aguas abajo y un ahorro en defensas e indemnizaciones. Es, en suma, un nuevo sistema de defensa, una estrategia de resiliencia (Vis et al., 2001) frente a las tradicionales estrategias de resistencia (diques, dragados, encauzamientos, etc.), en la línea de lo propuesto por la Directiva de Inundaciones (Comisión Europea, 2007).

- Al resolver problemas de ordenación de áreas inundables, el Territorio Fluvial contribuye a reducir la exposición, lo que implica sostenibilidad a la hora de luchar contra las situaciones de riesgo (Blackwell y Maltby, 2006; Ollero y Elso, 2007). Esta propuesta permite la multifuncionalidad de los espacios inundables, ya en el Territorio Fluvial se pueden desarrollar actividades humanas compatibles con la inundación o cubiertas con seguros. Puede esperarse que las presiones ejercidas sobre el territorio inundable sean menos intensas y más fácilmente recuperables.

- En suma, el Territorio Fluvial mejora y consolida el paisaje fluvial, que gana en naturalidad, y constituye la base imprescindible, tanto funcional como territorial, para la mitigación de riesgos, para la conservación de espacios fluviales y para la restauración (Brierley et al., 2008). Bien es cierto que para la auténtica autorestauración fluvial, no es suficiente con devolver un Territorio Fluvial al río, sino que hacen falta también crecidas, flujo de sedimentos, eliminar obstáculos transversales y rebajar terrenos colgados.

\subsection{Delimitación}

Dados sus caracteres, objetivos y condicionantes, el Territorio Fluvial debería estar delimitado por criterios geomorfológicos, ecológicos e históricos (evolución fluvial), y no debería contar con límites permanentes, sino revisados periódicamente, 
precisamente para adaptarse continuamente a la propia dinámica fluvial (Ureña y Ollero, 2000). En cauces meandriformes, el Territorio Fluvial debería abarcar como mínimo el cinturón de meandros. Es un espacio que viene a coincidir, por tanto, con la ZICG (Zona de Intenso Cambio Geomorfológico) definida por Ayala (2002). En ramblas deberían tenerse en cuenta espacios que, sin constituir la llanura de inundación propiamente dicha, vehiculan agua y resultan inundables a causa de la falta de organización de la red de drenaje (zonas arreicas de drenaje deficiente), corredores, paleocauces, abanicos aluviales, vaguadas laterales en llanuras convexas, yazoos...(Camarasa y Soriano, 2008).

Para la delimitación del Territorio Fluvial pueden emplearse los siguientes criterios, en su mayor parte emanados de la metodología francesa (Malavoi et al., 1998), pero adaptados a la situación concreta de los cursos fluviales de la Península Ibérica (figura 2):

- Inclusión dentro del Territorio Fluvial de los distintos trazados del cauce en el último siglo, consultando para ello cartografía y fotografías aéreas antiguas.

- Inclusión de toda la extensión del corredor ribereño en 1956-57 (fotografías aéreas del vuelo americano).

- Inclusión de terrenos susceptibles de ser erosionados en las próximas décadas por la propia dinámica del cauce.

- Inclusión de galachos, masas de vegetación ribereña aisladas y otros anexos fluviales desconectados del corredor ribereño.

- Podría también establecerse que quedara dentro del Territorio Fluvial toda la zona inundada por la crecida de 5 años (en ríos grandes) o la de 10 años (en cursos pequeños). En muchas ocasiones, sin embargo, los entornos inundados no coinciden con los estimados por los modelos hidráulicos basados en períodos de recurrencia (Camarasa y Bescós, 2004). Por ello, en caso de duda, debería estudiarse para cada cuenca, el período de retorno que coincide con la zona real de inundación habitual, con objeto de determinar un criterio hidráulico más acorde con la realidad geomorfológica.

- Exclusión de los núcleos de población.

- Mayor ensanchamiento del Territorio Fluvial aguas arriba y enfrente de núcleos de población para reducir los niveles o cotas de aguas desbordadas. 

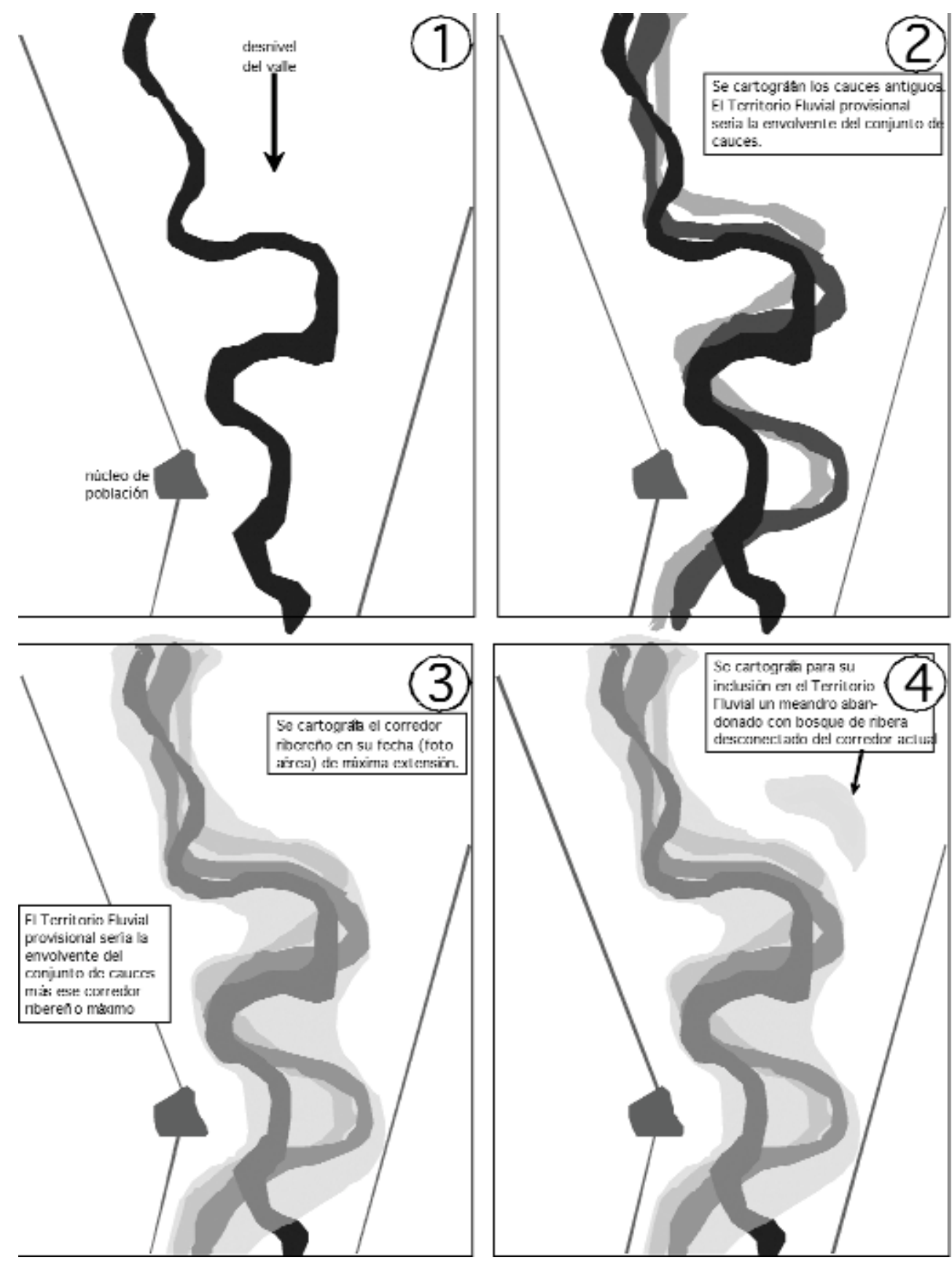


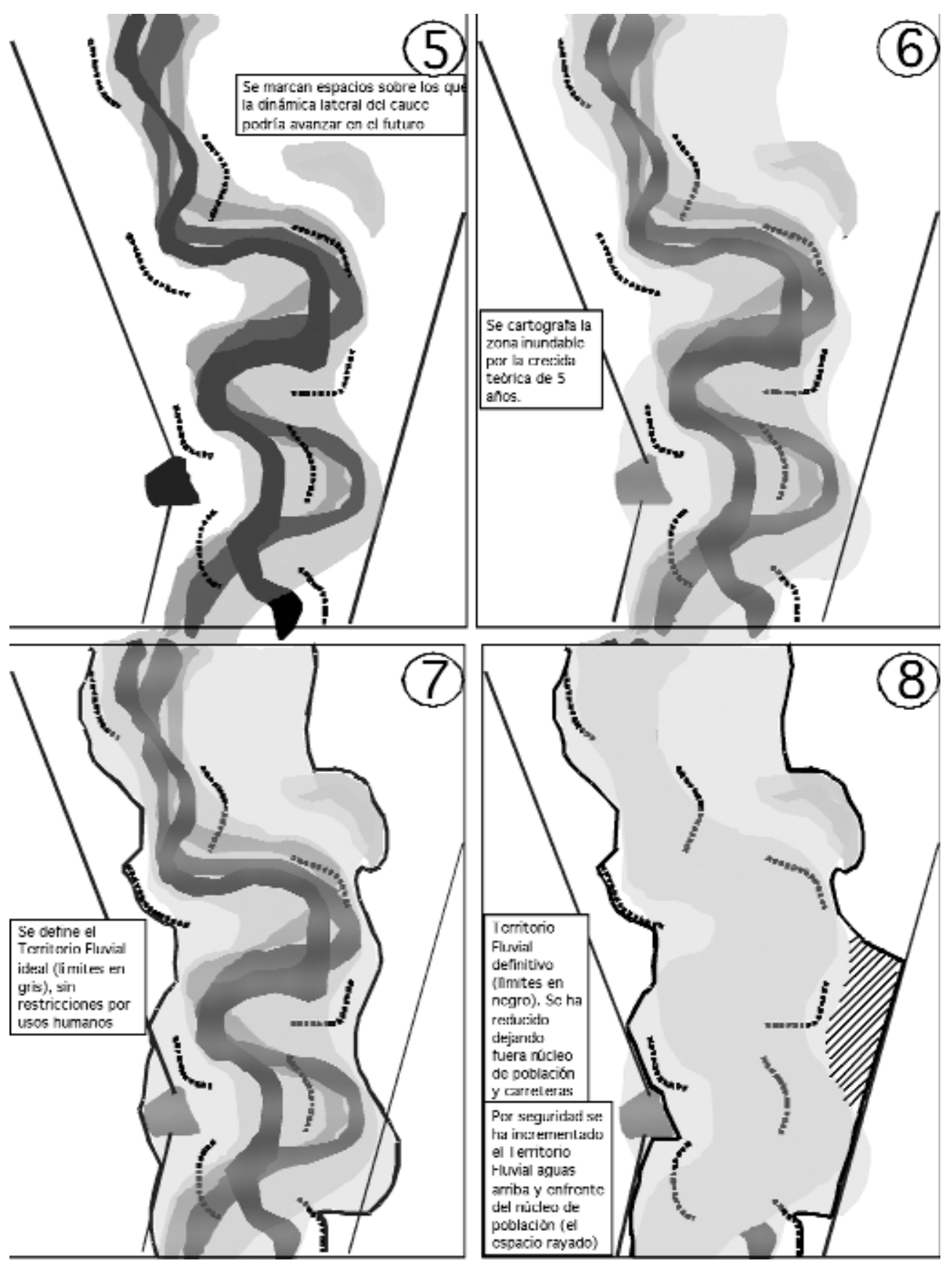

Figura 2. Proceso de delimitación del Territorio Fluvial. 


\subsection{Integración con los usos del suelo}

El establecimiento de este Territorio Fluvial exige en los llanos de inundación extensos de cursos dinámicos la eliminación de las defensas de margen (escolleras que evitan la erosión de las orillas y sujetan el cauce menor impidiendo su dinámica) y el alejamiento de los diques o motas longitudinales que protegen de la inundación hasta ubicarlos, si son necesarios, en los límites externos de este Territorio Fluvial. Es necesario restringir en él ciertos usos humanos del territorio y muy especialmente nuevas edificaciones.

Habría que tratar de potenciar el uso del Territorio Fluvial como área natural o con usos que no dificulten el desplazamiento del cauce y establecer medidas administrativas para potenciar estos usos. En áreas rurales, por ejemplo, se podría potenciar la concentración en este espacio de las superficies que, por razones administrativas, deban retirarse del cultivo (Ureña y Ollero, 2000). La creación del Territorio Fluvial podría ser bien acogida por los propietarios afectados si a cambio se establecieran medidas de ecodesarrollo que beneficiaran la rentabilidad de las huertas tradicionales, con subvenciones, promoción de los productos, denominación de origen de los mismos, descuentos en los cánones de regadío, fomento de actividades alternativas como el turismo fluvial, etc.

En las áreas urbanas el Territorio Fluvial, más estrecho, debería integrarse en áreas verdes o parques diseñados de manera que se mantuviera en alguna medida la continuidad del corredor fluvial. Los planes municipales de uso del suelo deberían definir para las áreas consolidadas por la urbanización los espacios que debe ser recuperados y los que deben ser dejados fuera de ordenación para que con el paso del tiempo puedan reintegrarse a la dinámica fluvial y por tanto al Territorio Fluvial. Deberían también establecer para dicho espacio usos del suelo compatibles con el desplazamiento lateral del cauce.

Las nuevas infraestructuras lineales paralelas al cauce (carreteras, ferrocarril, conducciones, etc.) deberían ubicarse fuera del Territorio Fluvial y las infraestructuras transversales deberían diseñarse para que el cauce pueda moverse.

Habría que asegurar la continuidad del Territorio Fluvial, estableciendo criterios comunes en la cascada de planes de ordenación territorial, desde los regionales, pasando por los comarcales, hasta los municipales, contando con una cartografía que delimite con precisión estos espacios. El Territorio Fluvial debería ser una figura con valor jurídico que obligue a todas las administraciones a aceptarla en su planificación.

Entre las restricciones en el Territorio Fluvial habría una fundamental, la prohibición de extracciones de áridos, como se estableció para el Espacio de 
Movilidad Fluvial en Francia (decreto de 24 de enero de 2001 del Ministerio de Medio Ambiente).

\section{Ejemplos de propuestas}

En los últimos años, en estudios aplicados realizados para los cursos bajos de los ríos Arga y Aragón (Díaz et al., 2002, Elso et al., 2008), Cinca medio (Ollero et al., 2001, 2002), bajo Gállego (Ollero y Martín Vide, dirs., 2005) y Ebro medio y bajo Cinca (Ollero et al., 2005), se ha propuesto la aplicación del Territorio Fluvial y se ha delimitado su anchura aconsejable en cada caso, empleándose la metodología de delimitación expuesta en el apartado 2.3. Por diferentes cuestiones administrativas, todas estas propuestas no han llegado ni siquiera a fase de proyecto.

\subsection{Río Ebro}

En el Plan Medioambiental del Ebro (Ollero et al., 2005), encargado por el Gobierno de Aragón a raíz de la crecida de febrero de 2003, se propuso un Territorio Fluvial continuo para el curso aragonés del Ebro de meandros libres, es decir, entre las localidades de Novillas y La Zaida. Dicho Territorio Fluvial alcanzaría una superficie total de 13.035 hectáreas, lo que implica una anchura media de $1.184 \mathrm{~m}$, es decir, un 30\% de la superficie total de la llanura de inundación. La aplicación de este territorio supondría retrasar las defensas una media de $350 \mathrm{~m}$ en cada margen (ejemplo en figura 3). Aproximadamente la mitad (6.705 ha) del Territorio Fluvial propuesto son en la actualidad terrenos de cultivo. En la figura 4 se representa la distribución de superficies de distintos tipos y usos del suelo integradas en la propuesta.

Aguas arriba, en el tramo navarro del Ebro medio, se ha procedido a la retirada de una defensa y a la consiguiente devolución de un espacio de 110 hectáreas al río en el Soto Tetones, propiedad comunal del municipio de Tudela.

\subsection{Río Cinca}

En el mismo Plan Medioambiental del Ebro se incluyó el curso bajo del río Cinca, con motivo de la grave problemática de inundaciones en la ciudad de Fraga (Ollero et al., 2005). El Territorio Fluvial propuesto para el bajo Cinca afecta a menos terrenos 


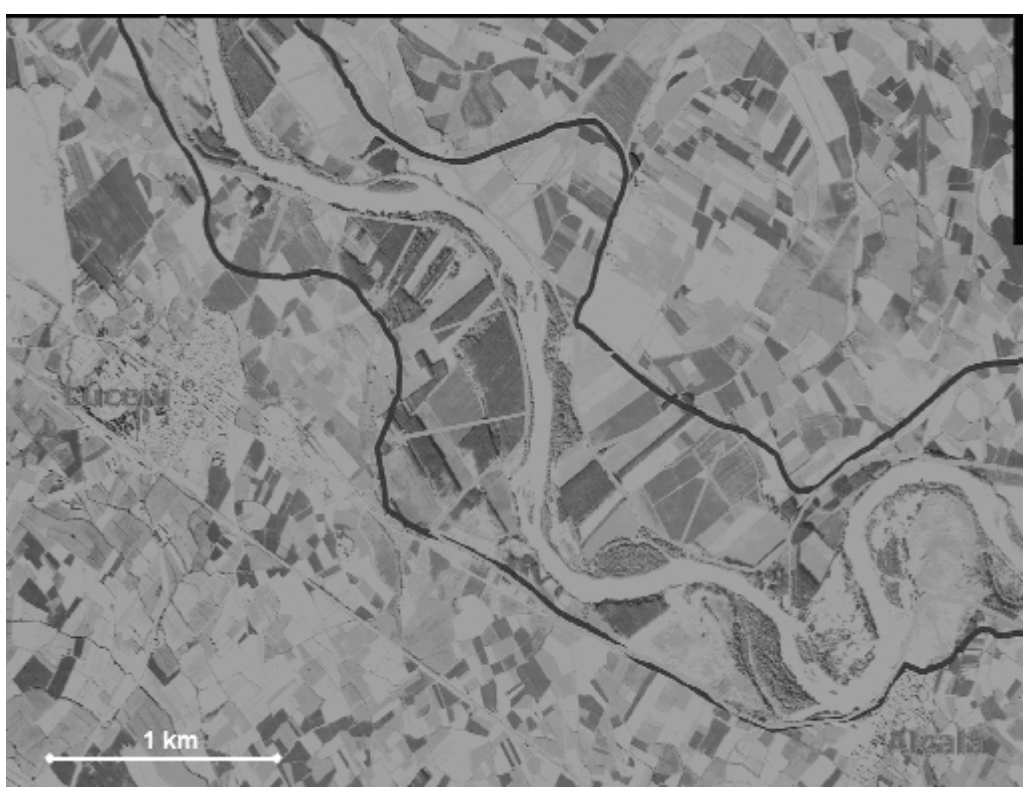

Figura 3. Propuesta de Territorio Fluvial y retroceso de defensas en un tramo del Ebro aguas arriba de Zaragoza (Ollero et al., 2005).

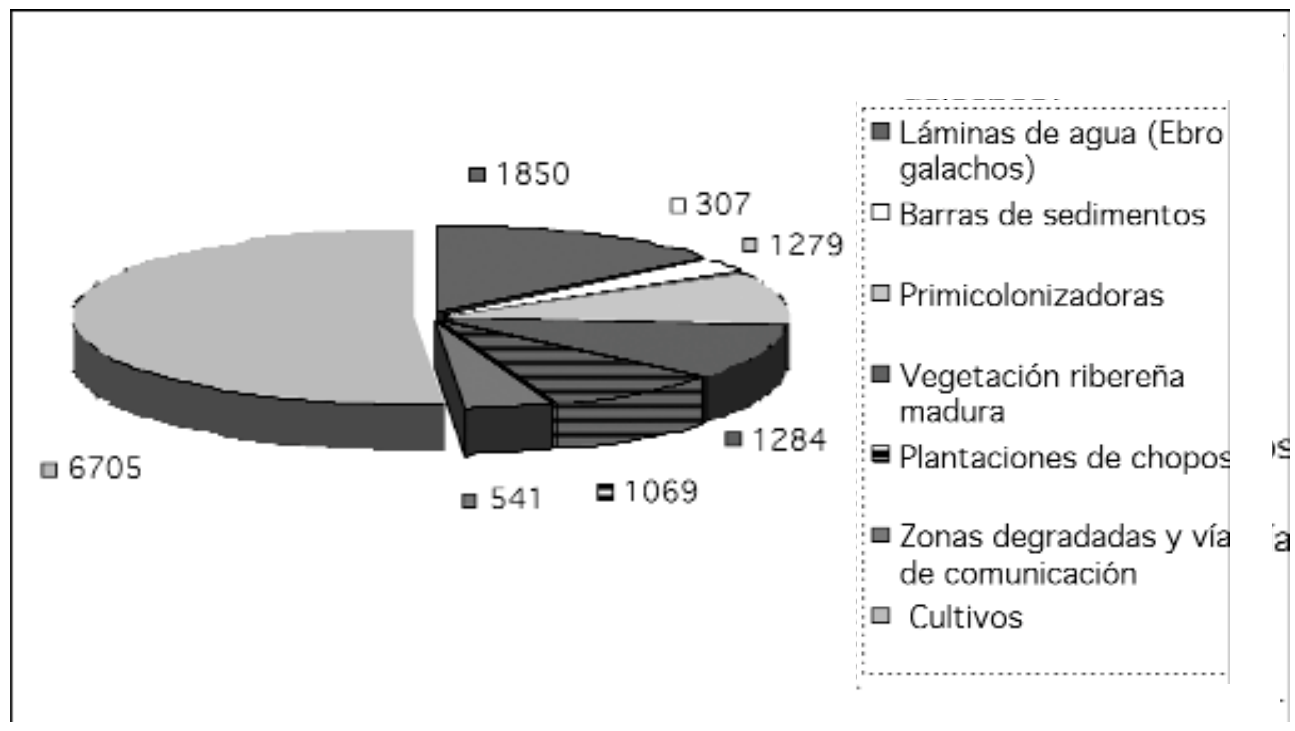

Figura 4. Superficie en hectáreas de los distintos usos del suelo integrados en el Territorio Fluvial propuesto para el Ebro entre Novillas y La Zaida (Ollero et al., 2005). 
de cultivo que el del Ebro, contando con un mayor equilibrio entre los distintos tipos de superficie y usos (figura 5). En total, estaría conformado por 1.621 hectáreas que representan una anchura media de $620 \mathrm{~m}$.

La retirada de defensas aguas arriba de Fraga para reducir las cotas inundación sería una medida muy útil que justificaría la conformación de un Territorio Fluvial. Una de las actuaciones emanadas de la Estrategia Nacional de Restauración de Ríos, ya realizada, ha sido la retirada de un dique secundario deteriorado de $7 \mathrm{~km}$ de longitud muy próximo al cauce.

\subsection{Río Gállego}

En el estudio desarrollado en el curso bajo del Gállego (Ollero y Martín Vide, dirs., 2005) se establecieron varias opciones o bandas posibles de Territorio Fluvial (figura 6):

- Territorio Fluvial Actual o Mínimo (TFA): espacio ocupado por el río (cauce más ribera) en la situación actual, equivalente al corredor ribereño. Se planteaba integrar en él únicamente equipamientos de ocio compatibles con la inundación y con el correcto funcionamiento de los ecosistemas. No deberían ubicarse infraestructuras ni edificaciones ni usos agrarios.

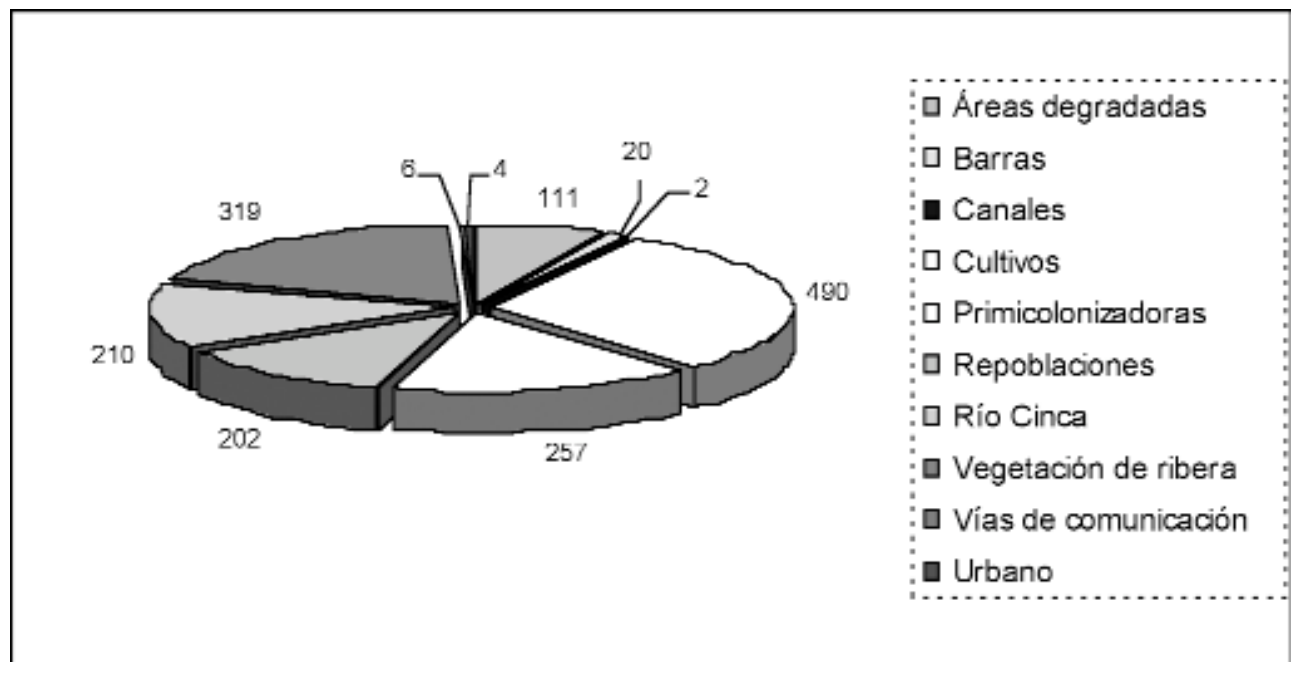

Figura 5. Superficie en hectáreas de los distintos usos del suelo integrados en el Territorio Fluvial propuesto para el bajo Cinca (Ollero et al., 2005). 


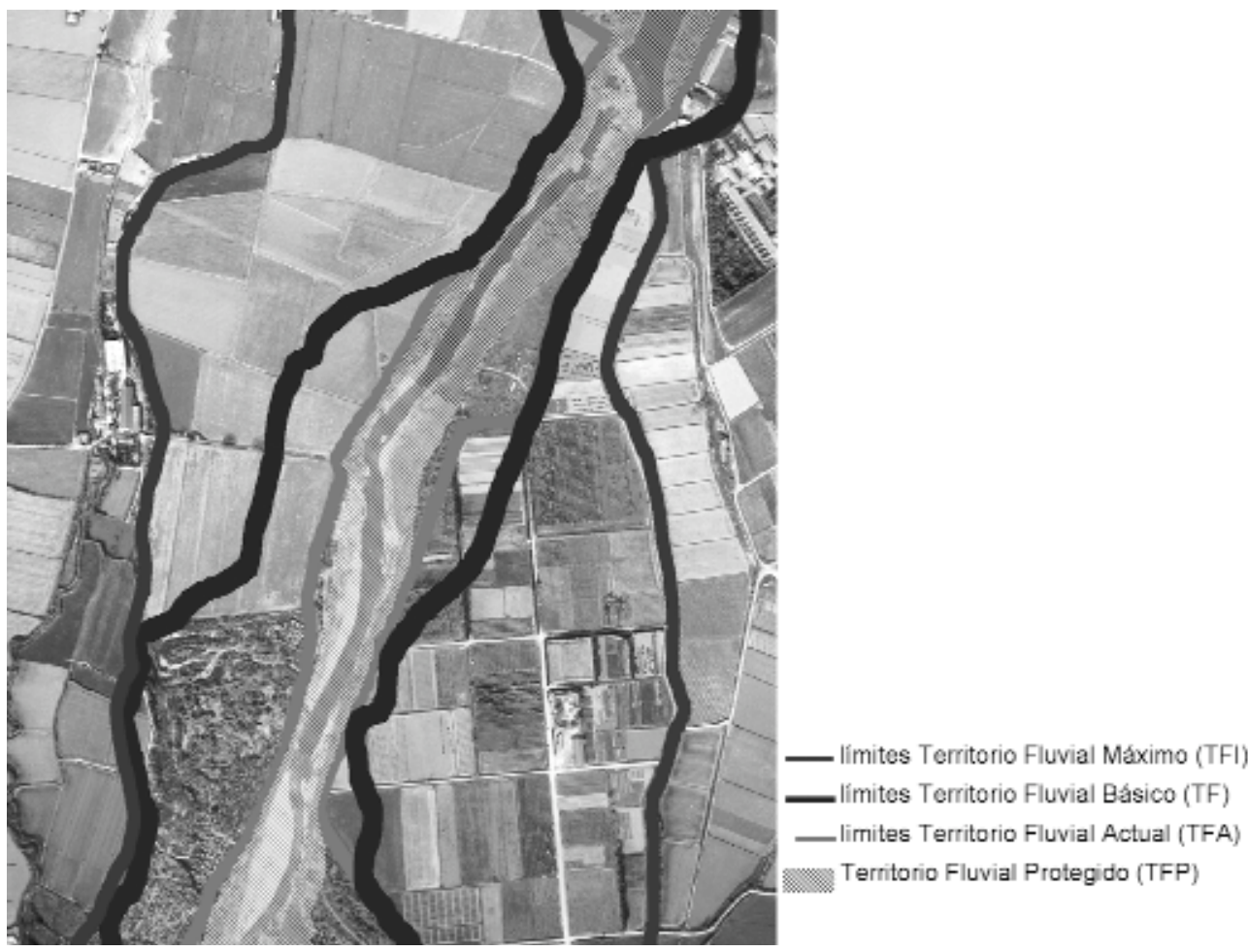

Figura 6. Propuesta de Territorio Fluvial para un tramo del curso bajo del Gállego (Ollero y Martín Vide, dirs., 2005).

- Territorio Fluvial Protegido (TFP): espacio perteneciente al río, integrado dentro del Territorio Fluvial Actual, que no debería ser objeto de ningún tipo de actuación o de ubicación de infraestructura alguna en el futuro, ni siquiera los equipamientos de ocio señalados en el TFA. Su objetivo es mantener la complejidad, continuidad y conectividad. Debería contar con una figura de protección legal.

- Territorio Fluvial Básico (TF): quedan englobados en su interior los dos territorios anteriores. Es un espacio fluvial más ancho que el actual, convirtiéndose en objetivo de planificación a corto y medio plazo. Es necesario restringir en él los usos humanos del territorio y muy especialmente nuevas edificaciones. Debe ser integramente inundable, de manera que las motas y defensas deberían establecerse fuera de sus límites. Su anchura media en el curso bajo del Gállego es de $470 \mathrm{~m}$. 
- Territorio Fluvial Ideal o Máximo (TFI): incluye la totalidad del llano de inundación. Debería ir logrando progresivamente, como objetivo a medio y largo plazo, una figura legal reconocida en la ordenación territorial como espacio que pertenece al río, aunque es compatible con actividades humanas e incluso con la edificación, y, por tanto, como espacio de riesgo. Debe asegurarse para toda la población integrada en el TFI una cultura fluvial y del riesgo, así como planes de emergencia y planes de seguros.

\subsection{Ríos Aragón y Arga}

En el plan de gestión del Lugar de Interés Comunitario ES2200035 "Tramos bajos de los ríos Aragón y Arga", se propuso el espacio continuo fluvial, antecedente del Territorio Fluvial, como uno de los elementos fundamentales de conservación de la biodiversidad en este espacio de la red Natura 2000 (Díaz et al., 2002).

Posteriormente, bajo diferentes proyectos cofinanciados por la Unión Europea, algunas de las acciones propuestas en el citado plan de gestión han ido ejecutándose, con lo que se ha ido poniendo en práctica, al menos parcialmente, ese Territorio Fluvial como solución que combina conservación de la biodiversidad, gestión de riesgos y ordenación de usos del suelo. La actuación más importante se llevó a cabo en el marco del proyecto LIFE "Gestión Ecosistémica de Ríos con Visón Europeo (GERVE)" (Elso et al., 2008), en el cual se trabaja en la recuperación del hábitat en las llanuras de inundación de una especie en peligro de extinción. Este proyecto ha sido premiado recientemente por la Comisión Europea como "Best of LIFE Award", destacándose la importancia del Territorio Fluvial como elemento armonizador entre conservación y gestión y su papel en la aplicación conjunta de tres directivas europeas: la de hábitats (1992/43/CE), la del agua (2000/60/CE) y la de riesgos de inundación $(2007 / 60 / \mathrm{CE})$.

En el proyecto GERVE se ha establecido el Territorio Fluvial en algunas zonas piloto mediante la retirada de diques o escolleras, llegando a recuperar en algunos puntos la naturalidad de la llanura de inundación. La recuperación de este territorio inundable ha mitigado el riesgo de inundación aguas abajo, como se constató en la localidad de Funes en el invierno de 2007. La recuperación de la llanura de inundación también ha hecho posible la restauración de los bosques ribereños y la creación de pequeños humedales, hábitats que han sido rápidamente colonizados por el visón europeo y otras especies de interés de conservación como la nutria o el galápago europeo. Además de estas acciones de restauración se ha desarrollado una campaña de comunicación para explicar en las localidades ribereñas este nuevo concepto de gestión fluvial y sus beneficios. 
El éxito del proyecto animó al Gobierno de Navarra a entrar en acción a mayor escala y en la actualidad ha puesto en marcha estudios geomorfológicos, hidráulicos y ecológicos de los cursos bajos de los ríos Arga y Aragón, definiéndose el Territorio Fluvial en estos tramos completos. Esta definición será el elemento clave en el que se asentará la gestión de las inundaciones y la conservación de la biodiversidad.

\section{Dificultades de aplicación}

Es evidente que aplicar el territorio Fluvial cuenta con importantes dificultades en la mayor parte de los ríos. Se trata principalmente de conflictos de propiedad, multiplicidad de usos e intereses de complicada compatibilización, situaciones heredadas, así como de la propia dificultad para integrar esta medida con la gestión de caudales y otras medidas ambientales. En España las posibilidades de aplicación son actualmente mínimas.

\subsection{Problemática de aplicación en España}

En la situación actual (octubre de 2009) la implementación del Territorio Fluvial en cursos de agua del estado español puede ser diagnosticada como inviable. Supondría una auténtica revolución en la gestión fluvial y es considerada irrealizable por las administraciones competentes. Las causas de esta situación son las siguientes:

- La enorme presión económica y urbanística sobre los fondos de valle en el último medio siglo. Los espacios fluviales están densamente ocupados por cultivos, edificios, vías de comunicación, infraestructuras, etc.

- El interés en mantener el actual estatus de la red fluvial como fuente de recursos (agua, áridos, el propio espacio...), de manera que en la práctica priman todas las demandas socioeconómicas frente a una escasísima o nula preocupación por las problemáticas ambientales. Por ejemplo, las concesiones se mantienen aun cuando se haya reducido el caudal de muchos ríos, siendo imposible cumplir con los caudales ambientales.

- La lenta e incompleta implementación de las directivas ambientales europeas, en especial la 2000/60/CE, ocultando en muchas ocasiones el verdadero estado de las masas de agua, que en general no se evalúa adecuadamente.

- Las enormes deficiencias normativas sobre los espacios públicos, en este caso manifestadas en la mínima aplicación legal de la figura del Dominio Público 
Hidráulico. Los deslindes, un cuarto de siglo después de la entrada en vigor de la ley, se han ejecutado en menos del 10\% de la longitud de la red fluvial, y siguiendo trazados muy discutibles.

- El consolidado proteccionismo legal con la propiedad privada. La administración fluvial no quiere enfrentarse a la expropiación y en todo caso optaría por la compra de terrenos. Y ello a pesar de que la mayor parte de la propiedad privada procede de invasiones alegales del espacio fluvial registradas hace 40 ó 50 años y luego consolidadas catastralmente.

- La erosión fluvial se ve social y administrativamente como pérdida de terreno que puede llevar a conflictos legales. Así, puede llegar a admitirse un Territorio Fluvial para laminar inundaciones, pero nunca un espacio de movilidad sin defensas de margen.

- La convergencia de distintas administraciones en la gestión del espacio fluvial, lo cual origina tanto conflictos como vacíos de responsabilidad y acción.

- La falta de recursos económicos de la administración local, que parece la mejor predispuesta a iniciativas como ésta, al menos en algunos casos en los que en el territorio fluvial domina el suelo municipal.

- La inexistencia de una cultura ambiental en las comunidades ribereñas, que frente a los problemas generados por las crecidas solo demandan, con el apoyo de los medios de comunicación, dragados, limpiezas de vegetación y defensas. Los organismos de cuenca suelen satisfacer estas demandas y no quieren esforzarse en explicar otras alternativas.

- La ausencia de antecedentes como planes de gestión o "acuerdos de río", ya que ninguna de estas iniciativas ha prosperado, o se encuentran en fases muy iniciales.

\subsection{Algunos puntos de apoyo}

A pesar de las dificultades descritas, es posible encontrar algunos puntos que pueden servir de base para que puedan surgir a medio y largo plazo aplicaciones del Territorio Fluvial en España.

- La Estrategia Nacional de Restauración de Ríos, lanzada en 2007 y ralentizada en 2009, pero que ha implicado a la administración estatal y ha sido capaz de despertar la conciencia social sobre esta temática. 
- En Cataluña han aparecido en la gestión hídrica y fluvial algunos conceptos muy relacionados con el Espacio de Movilidad. Así, cada estudio de planificación para las diferentes cuencas internas de Catalunya propone la delimitación de tres figuras en el Espacio Fluvial -Zona Fluvial, Sistema Hídrico y Zona Inundable(Agència Catalana de l'Aigua, 2002, 2006) que se han transpuesto en el Reglamento de la Llei d'Urbanisme y que están ya en vigor desde el mes de julio de 2006. En el artículo 6 de este reglamento se especifican los usos admitidos en cada figura.

- El trabajo científico y técnico de muchos expertos del medio ambiente y los sistemas fluviales, desde proyectos de investigación y contratos con la administración, se va desarrollando de forma creciente y cuenta con el Territorio Fluvial como uno de los aspectos clave en la mejora y restauración fluvial.

- En la misma línea, la creación en 2009 del Centro Ibérico de Restauración Fluvial, integrado en el European Centre for River Restoration, que aglutina a profesionales e iniciativas de trabajo y que defiende el Territorio Fluvial como campo básico de actuación en el futuro.

- El interés de muchas entidades locales por resolver sus problemas de riesgos, lo cual ha llevado a que contemplen el Territorio Fluvial como una posibilidad útil y factible.

\section{Perspectivas}

El Territorio Fluvial está científicamente consolidado como modelo de actuación y es técnicamente viable. Sin embargo, apenas es tenido en cuenta en los ámbitos políticos y administrativos. Al presentar dificultades de aplicación y gestión, no es todavía apreciado como solución a las problemáticas ambientales y de riesgos. A lo largo de los últimos años se han observado avances en torno a esta idea en diferentes países europeos. No es este el caso de España, donde parece que hará falta más tiempo para vencer las notables inercias que impiden estas nuevas fórmulas de restauración fluvial.

Dado que los objetivos ambientales en los sistemas fluviales generan muy escaso interés en las administraciones españolas, la vía por la que es más factible un incremento del interés por el Territorio Fluvial es su utilidad en la reducción del riesgo por inundaciones. 
Han surgido algunas iniciativas recientes de aceptación de la inundación controlada de espacios fluviales agrarios. Sin embargo, al no aceptarse la erosión fluvial, por cuanto puede generar pérdida de propiedad privada, no se han logrado auténticos territorios fluviales, sino tan solo espacios temporalmente inundables. Un ejemplo muy expresivo se encuentra en el curso medio del Ebro aguas arriba de Zaragoza. Durante las crecidas de abril de 2007 y junio de 2008 y para salvaguardar las obras de la Exposición Internacional de Zaragoza 2008, ubicadas en zona urbana inundable, se actuó rompiendo diques aguas arriba (Espejo et al., 2008), reduciéndose así las puntas de crecida. A raíz de aquellas situaciones, la Confederación Hidrográfica del Ebro constituyó una comisión técnica en la que se discutieron dos posibilidades de actuación: i) permeabilizar con compuertas todos los diques logrando áreas de inundación controlada en la propia llanura de inundación del Ebro (capacidad de $53 \mathrm{hm}^{3}$ aguas arriba de Zaragoza en la crecida con un periodo de retorno de 10 años) ó ii) demoler las defensas que protegen de la inundación de 10 años y establecer un nuevo cordón de diques continuos en el límite de la crecida con un periodo de retorno de 25 años. El organismo de cuenca aprobó la primera de las dos opciones. Con ello, ejerce el control de la inundación manteniendo las orillas estables y los actuales límites de propiedad y usos del suelo. Sin embargo, esta medida no aporta ningún beneficio ambiental al sistema fluvial, que sigue constreñido entre defensas de margen, consolidándose una vez más la ocupación humana del espacio fluvial que se ejerció de forma alegal hace 50 años. El Ebro medio sigue sin contar, por tanto, con un Territorio Fluvial.

Es urgente lograr poner en práctica el Territorio Fluvial en algún tramo de alguno de nuestros ríos, como ejemplo de demostración que pueda animar a otros casos y también para realizar sobre ese espacio un seguimiento científico de procesos y tendencias.

En la situación actual sería viable que muchos sistemas fluviales puedan lograr un Territorio Fluvial en un plazo relativamente corto de tiempo, si existiera voluntad para ese objetivo en los gestores del territorio. Podría ser necesaria una importante inversión económica inicial para retirar defensas o desplazarlas, para comprar o expropiar terrenos, para favorecer cambios en los usos del suelo y para cofinanciar seguros para aquellos propietarios que prefieran mantener su actividad dentro del Territorio Fluvial y, por tanto, a expensas de la inundación y de la erosión fluvial. Ahora bien, si se logra el Territorio Fluvial, la necesaria restauración del cauce y las riberas, tan degradados en las últimas décadas, la llevará a cabo el río, por lo que será muy barata. Tan sólo requerirá posiblemente alguna ayuda puntual en la rehabilitación de algunos procesos en terrenos muy alterados.

El Territorio Fluvial es aplicable a cualquier curso fluvial, incluyendo pequeños barrancos y ramblas. Simplemente habría que adaptar algunos criterios y reforzar 
ciertos condicionantes. Sin embargo, si la aplicación a grandes cursos de agua se ve aún lejana, necesitada de la convergencia de varias voluntades y posibilidades, la aplicación a cursos modestos se antoja utópica por el momento. Son sistemas fluviales a los que se ha perdido totalmente el respeto y en los que se han ejecutado transformaciones y alteraciones enormes, a veces definitivas. No todos los problemas fluviales han de ser resueltos con obras de ingeniería, sino que son muy factibles las soluciones de ordenación territorial.

La reducción de la peligrosidad de crecidas e inundaciones que generaría el Territorio Fluvial es importante. Pero es imprescindible además educar a la población en el riesgo, en el funcionamiento de los sistemas fluviales y en la convivencia con los mismos. Porque es preciso, y posible, eliminar la connotación negativa de crecidas e inundaciones para la sociedad, si ésta se encuentra preparada en un territorio bien ordenado.

Dentro del Territorio Fluvial y a partir de una bien pensada zonificación de usos del suelo será posible mantener actividades humanas y recuperar el aprovechamiento recreativo de ríos y riberas, también conservar y mejorar su impresionante valor escénico, así como otras muchas iniciativas de desarrollo sostenible. El Territorio Fluvial puede ser también una seña de identidad sociocultural. Pero por encima de todo, lo que se logrará con esta propuesta es que los ríos sean realmente ríos y puedan funcionar como tales.

\section{Conclusión}

El Territorio Fluvial es una solución sencilla y de sentido común frente a la problemática ambiental y de riesgos de los ríos de llanura. Se ha justificado la necesidad de proteger la dinámica natural de los sistemas fluviales como clave para su correcta gestión territorial, para la mejora de sus ecosistemas y para la minimización de los riesgos. La primera solución para el mantenimiento o recuperación de esa dinámica que la devolución al río de al menos una parte de su territorio. Respetar (o devolver) el Territorio Fluvial es, ante todo, una medida inteligente. Frente a las habituales medidas de choque contra el río o de resistencia, es una estrategia de adaptación, de resiliencia. Cuanto mejor se respete y conserve el territorio del río mejor funcionará el sistema fluvial y más beneficios aportará. 


\section{Bibliografía}

Agència Catalana de l'Aigua (2002) Criteris d'intervenció en espais fluvials. Barcelona, Generalitat de Catalunya.

Agència Catalana de l'Aigua (2006) Directrius de planificació i gestió de l'espai fluvial. Guia tècnica. Barcelona, Generalitat de Catalunya.

Ayala, F.J. (2002) Estrategias y medidas de mitigación del riesgo de inundaciones. Gestión de zonas inundables. In Ayala, F.J. y Olcina, J. (Coords): Riesgos naturales, 977-995, Barcelona, Ariel.

Bazin, P. y Gautier, E. (1996) Un espace de liberté pour la Loire et l'Allier: de la détermination géomorphologique à la gestion. Revue de Géographie de Lyon, 71(4): 377386.

Blackwell, M.S.A. y Maltby, E. (2006) Ecoflood guidelines. How to use floodplains for flood risk reduction. Luxembourg, European Community, EUR22001.

Brierley, G.J.; Fryirs, K.A.; Boulton, A. y Cullum, C. (2008) Working with change: the importance of evolutionary perspectives in framing the trajectory of river adjustment. In Brierley, G.J. y Fryirs, K.A. (eds.) River futures. An integrative scientific approach to river repair, 65-84, Washington, Society for Ecological Restoration International, Island Press.

Brookes, A. (1996) Floodplain restoration and rehabilitation. In Anderson, M.G.; Walling, D.E. y Bates, P.D. (eds.) Floodplain processes, 553-576, Chichester, Wiley.

Camarasa, A.M. y Bescós, A. (2004) Cartografía de áreas inundables: comparación entre mapas de peligro y mapas de inundaciones concretas. Riesgos Naturales y Antrópicos en Geomorfología, 2: 25-36. Sociedad Española de Geomorfología.
Camarasa, A.M. y Soriano, J. (2008) Peligro, vulnerabilidad y riesgo de inundación en ramblas mediterráneas: los llanos de Carraixet y Poyo. Cuadernos de Geografia, 83, 1-26.

Cals, M.J.R. y van Drimmelen, C. (2000): Space for the river in coherence with landscape planning in the Rhine-Meuse Delta. In Nijland, H.J. \& Cals, M.J.R. (Eds.): River Restoration in Europe: practical approaches. Wageningen, European Centre for River Restoration.

Chorley, R.J. y Kennedy, B.A. (1971) Physical Geography: a systems approach. London, Prentice Hall.

Comisión Europea (1992) Directiva 92/43/CE del Consejo relativa a la conservación de los hábitats naturales y de flora y fauna silvestres. Diario Oficial L-206 de 22/07/1992, 7-50.

Comisión Europea (2000) Directiva 2000/ 60/CE del Parlamento Europeo y del Consejo por la que se establece un marco comunitario de actuación en el ámbito de la política de aguas. Diario Oficial L-327 de 22/12/2000, 1-73.

Comisión Europea (2007) Directiva 2007/ 60/CE del Parlamento Europeo y del Consejo relativa a la evaluación y gestión de los riesgos de inundación. Diario Oficial L-288 de 6/11/2007, 27-34.

Department of Water Resources, State of California (1998) Sacramento River conservation area handbook. Resources Agency State of California (unpublished report).

Díaz, E.; Ibisate, A. y Ollero, A. (2002) Elemento clave: espacio continuo fluvial. Plan de gestión del Lugar de Interés Comunitario ES2200035 "Tramos bajos del Aragón y del Arga". Gestión Ambiental 
Viveros y Repoblaciones de Navarra, para el Gobierno de Navarra.

Dister, E.; Gomer, D.; Orbdlik, P.; Petermann, P. y Schneider, E. (1990) Water management and ecological perspectives of the Upper Rhine's floodplains. Regulated Rivers Research and Management, 5(1): 115.

Elso, J.; Urra, F.; Mendoza, F. y Moreno, S. (2008): Biodiversity conservation and river restoration: from planning to execution through a Life Project in Aragón River, Navarra, Spain. Curso avanzado "Restauración ecológica de ríos mediterráneos". Zaragoza, Instituto Agronómico Mediterráneo.

Espejo, F.; Domenech, S.; Ollero, A. y Sánchez Fabre, M. (2008) La crecida del Ebro de 2007: procesos hidrometeorológicos y perspectivas de gestión del riesgo. Boletin de la Asociación de Geógrafos Españoles, 48, 129-154.

Forman, R.T.T. y Godron, M. (1986) Landscape ecology. New York, Wiley.

Govi, M. y Turitto, O. (1994) Problemi di riconoscimento delle fasce di pertinenza fluviale. In Difesa e valorizzazione del suolo e degli acquiferi. Proceedings IV Convegno Internazionale di Geoingegneria, 161-172, Torino.

Guerrero, I. y Baena, R. (2002) Geomorfología fluvial y restauración ambiental: el ejemplo del río Guadiamar en la zona de Entremuros (Parque Natural de Doñana). Estudios recientes (2000-2002) en Geomorfología. Patrimonio, montaña $y$ dinámica territorial, 79-90, Universidad de Valladolid.

Habersack, H. y Piégay, H. (2007) River restoration in the Alps and their surroundings: past experiences and future challenges. In Rinaldi, M.; Habersack, H. y Piégay, H. (eds.) Gravel bed rivers 6: from process understanding to the restoration of mountain rivers. Elsevier.

Junk, W.J.; Bayley, P.B. y Sparks, R.E. (1989) The flood-pulse concept in river-floodplain systems. In Dodge, D.P. (ed.) Proceedings of the International Large River Symposium. Special Publ. of the Canadian Journal of Fisheries and Aquatic Sciences, 106: 110-127.

Kondolf, G.M.; Piégay, H. y Sear, D. (2003) Integrating geomorphological tools in ecological and management studies. In Kondolf, G.M. y Piégay, H. (eds.) Tools in Fluvial Geomorphology, 633-660, Chichester, Wiley.

Leopold, L.B.; Wolman, M.G. y Miller, J.P. (1964) Fluvial processes in Geomorpho$\operatorname{logy}$. San Francisco, Freeman.

Malavoi, J.R.; Bravard, J.P.; Piégay, H.; Héroin, E. y Ramez, P. (1998) Determination de l'espace de liberté des cours d'eau. Lyon, SDAGE Rhône-Méditerranée-Corse.

Malavoi, J.R.; Gautier, J.N. y Bravard, J.P. (2002) Free space for rivers: a geodynamical concept for a substainable management of the watercourses. In Bousmar, D. y Zech, Y. (Eds.) Proceedings of the International Conference on Fluvial Hydraulics River Flow 2002, Swets \& Zeitlinger, Lisse, Nederland.

Mateu, J.F. (1990) Avenidas y riesgos de inundación en los sistemas fluviales mediterráneos de la Península Ibérica. Boletín de la Asociación de Geógrafos Españoles, 10, 4586.

Montes, C. (2002): Lecciones aprendidas en tres años de restauración de ecosistemas en el corredor verde del Guadiamar. Ecosistemas, XI(1), informes.

Ollero, A. (1993a) Programa de planificación y recuperación del espacio ribereño del corredor del Ebro (tramo Novillas-Pina) 
con fines medioambientales y recreativos. In Arqued, V.; Gaviria, M.; Ollero, A. y Omedas, M. (coords.) La hidridación integrada del corredor del Ebro. Informe inédito. Confederación Hidrográfica del Ebro

Ollero, A. (1993b) Aménagement et gestion e l'Ebre dans la région de Saragosse: un projet de récupération écologique et sociale du système fluvial. Actes du Colloque "Aménagement et gestion des grandes rivières méditerranéennes, Études Vauclusiennes, 5: 79-83.

Ollero, A. (1993c) L'aménagement de l'Ebre moyen à méandres libres: la progression des activités humaines sur le système litberges et ses conséquences. Actes $d u$ Colloque International "Le fleuve et ses metamorphoses", 263-270, Lyon, Université Jean Moulin.

Ollero, A. (2006) Inundaciones y ordenación del territorio fluvial en la cuenca del Ebro. In Chastagnaret, G. y Gil Olcina, A. (eds.) Riesgo de inundaciones en el Mediterráneo occidental, 239-272, Madrid, Casa de Velázquez.

Ollero, A. (2007) Territorio fluvial. Diagnóstico y propuesta para la gestión ambiental $y$ de riesgos en el Ebro y los cursos bajos de sus afluentes. Bilbao, Bakeaz.

Ollero, A. (coord., 2007) Las alteraciones geomorfológicas de los ríos. In González del Tánago, M. (coord.): Estrategia Nacional de Restauración de Ríos. Madrid, Ministerio de Medio Ambiente.

Ollero, A.; Cadiñanos, J.A.; Díaz, E.; Elosegi, U.; García, F.; Ibisate, A.; Meaza, G.; Ormaetxea, O. y Sáenz de Olazagoitia, A. (2001) Análisis y diagnóstico del sistema fluvial y propuestas para la gestión de un tramo regulado en el río Cinca (Huesca). Actas del XVII Congreso de Geógrafos Españoles, 185-188, Oviedo, Asociación de Geógrafos Españoles.
Ollero, A.; Miguélez, E.; Sánchez, R. y Elosegi, U. (2002) Análisis, diagnóstico y propuestas para la gestión del río Cinca en el tramo Presa de El Grado-Confluencia del Vero. Somontano, 7, 7-31.

Ollero, A.; Ballarín, D. y Mora, D. (2005) El fundamento ambiental del Plan: una dinámica fluvial natural activa. Monográfico 2 del Plan Medioambiental del Ebro y tramo bajo del Cinca. Zaragoza, Gobierno de Aragón.

Ollero, A. y Martín Vide, J.P. (dirs., 2005) Estudio bidrológico, geomorfológico, bidráulico y ecológico del bajo Gállego en el T.M. de Zaragoza para su gestión como espacio fluvial. Convenio de investigación Ayuntamiento de Zaragoza-Universidad de Zaragoza-Universitat Politécnica de Catalunya (inédito).

Ollero, A. y Elso, J. (2007) The need for a "fluvial territory" or "room for the river": living with floods by acceptance of their functions. In Baker, C. \& van Eijk, P. (eds.) Sustainable flood management: obstacles, challenges and solutions, 59-63, Maastricht, Interreg IIIC Network FLAPP.

Palmer, L. (1976) River management criteria for Oregon and Washington. In Coates, D.R. (ed.) Geomorphology and Engineering, 329-346. Stroudsburg, Dowden, Hutchinson \& Ross.

Piégay, H.; Barge, O.; Bravard, J.P.; Landon, N. y Peiry, J.L. (1996a) Comment delimiter l'espace de liberté des rivières. Congrès de la Société Hydrotechnique de France, 24émes Journées de l'Hydraulique: l'eau, l'homme et la nature, 275-284, Paris, Société Hydrotechnique de France.

Piégay, H., Barge, O. y Landon, N. (1996b) Streamway concept applied to river mobility / human use conflict management. First International Conference on New/Emerging Concepts for Rivers. 
Proceedings Rivertech 96, 681-688, Tockner, K.; Malard, F. y Ward, J.V. (2000) An I.W.R.A. extension of the Flood Pulse concept. Hydrological Processes, 14, 2861-2883.

Piégay, H.; Darby, S.E.; Mosselman, E. y Surian, N. (2005) A review of techniques available for delimiting the erodible river corridor: a sustainable approach to managing bank erosion. River Research and Applications, 21, 773-789.

Pottier, N.; Penning-Rowsell, E.; Tunstall, S. y Hubert, G. (2005) Land use and flood protection: contrasting approaches and outcomes in France and in England and Wales. Applied Geography, 25, 1-27.

Rapp, C.F. y Abbe, T.B. (2003) A framework for delineating channel migration zones. Washington State Dpt. of Ecology \& Dpt. of Transportation.

Rohde, S.; Schütz, M.; Kienast, F. y Englmaier, P. (2004) River widening: an approach to restoring riparian habitats and plant species. River Research and Applications. 21(10), 1075-1094.

Rohde, S.; Hostmann, M.; Peter, A. y Ewald, K.C. (2006) Room for rivers: an integrative search strategy for floodplain restoration. Landscape and Urban Planning, 78(1-2), 50-70.

Roux, A.L. (Ed., 1982) Cartographie polythématique appliquée a la gestion écologique des eaux. Etude d'un bydrosystème fluvial: le Haut-Rbône français. Lyon, C.N.R.S.

Schumm, S.A. (1977) The fluvial system. New York, Wiley.

Ureña, J.M. (Ed., 1999) River design and environmental protection in Europe. Santander, Universidad de Cantabria.

Ureña, J.M. y Ollero, A. (2000) Criterios y propuestas para la ordenación de áreas fluviales. Ciudad y territorio, Estudios Territoriales, XXXII(126), 689-710.

Ureña, J.M. y Ollero, A. (2001) Fluvial landscapes, catchment administration and land-use planning: experience based on two rivers in Spain. Landscape Research, 26(3), 225-243.

Vannote, R.L.; Minshall, G.W.; Cummins, K.W.; Sedell, J.R. y Cushing, C.E. (1980) The river continuum concept. Canadian Journal of Fisheries and Aquatic Science, 37, 130-137.

Vis, M.; Klijn, F. y Buuren, M. van (Eds., 2001) Living with floods. Resilience strategies for flood risk management and multiple land use in the lower Rhine River basin. Delft, The Netherlands Centre for River Studies.

Ward, J.V. y Stanford, J.A. (1983) The serial discontinuity concept of lotic ecosystems. In Fontaine, T.D. \& Bartell, S.M. (eds.) Dynamic of lotic ecosystems, 347-356, Ann Arbor, Ann Arbor Science.

Ward, J.V. y Stanford, J.A. (1995) The serial discontinuity concept: extending the model to floodplain rivers. Regulated Rivers, 10, 159-168. 